\title{
Rússia: o que vivenciou e o que tem pela frente?
}

TATIANA ZASLAVSKAIA

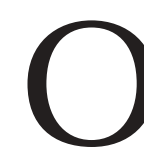

OBJETIVO deste artigo consiste em responder às questões essenciais que foram indicadas no programa do Simpósio Para ondevai a $R$ ússia? A fim de fundamentar mais precisamente o objeto das discussões e ativá-las, formularei sucintamente minhas reflexões sobre os resultados de quinze anos de transformações da sociedade russa.

A primeira questão diz respeito à natureza social, ou à tipologia desse processo. N a literatura científica e nas apresentações feitas neste Simpósio, surgiram distintos pontos de vista sobre essa questão. De acordo com um deles, ocorreu na Rússia uma Granderevol ução li beral-democrática ${ }^{1}$, conduzida contra o regime burocrático-autoritário soviético, que refreava a modernização da sociedade². O segundo ponto de vista (contrário em sua substância) sustenta que as reformas realizadas neste período continuaram e levaram a um fim lógico o golpe antisocialista, levado a cabo por Stalin ainda no final dos anos de $1920^{3}$.

D e acordo, porém, com um ponto de vista mais difundido, que eu compartilho, nos anos de 1980-1990 amadureceu uma revolução democrática, dirigida contra o poder autoritário da nomenklatura partidária. M as as forças do protesto social não se revelaram suficientemente maduras para tomar em suas mãos 0 poder e realizar reformas construtivas no interesse da maioria da população. 0 ânimo revolucionário caiu rapidamente e no poder permaneceu praticamente essa mesma nomenklatura, que o utiliza em seus próprios interesses.

Assumir um desses pontos de vista depende da avaliação que se faça, tanto da situação contemporânea, como do provável futuro da Rússia. É importante compreender se real mente, mesmo não sabendo, vivenciamos uma revolução social e, se "sim", então quando e qual? Q uais foram as forças so ciais que se confrontaram em guerra irreconciliável? Q uem ganhou e quem perdeu essa guerra? Q ue for ças político-sociais chegaram ao poder e no interesse de quem utilizaram esse poder?

$\mathrm{N}$ a opinião de $\mathrm{V}$. A. M au, os acontecimentos que tiveram lugar na Rússia na primeira metade dos anos de 1990, foram marcados por uma série de particularidades, que são características às revoluções. São elas: 1) natureza sistêmica, profundidadee radicalização das mudanças das instituições básicas; 2) condicionamento das transformações primordial mente pelascontradi çõesi nternas de uma dada sociedade; 3) fraqueza do poder político e ausência de acordo social a respeito de problemas, objetivos e valores centrais; 4) incapacidade da elite no poder 
de consoli dar a sociedade para a realização "pacífica" de transformações sistêmicas, brusco fortalecimento da espontaneidade dos processos sociais ${ }^{4}$.

Penso, entretanto, que esta argumentação não é suficientemente convincente. $\mathrm{N}$ ão há dúvida de que as reformas realizadas nesse período tocaram em importantes características societais, o que permite considerá-las revolucionárias. $M$ as isso não as iguala a revolução. Contra esse tratamento dos acontecimentos russos de começo dos anos de 1990 colocam-se as seguintes considerações: 1) 0 sujeito das revolu ções sociais são as forças sociais de massa, que to mam consciência da não conciliação de seus interesses vitais com os interesses das classes dirigentes; na Rússia, entretanto, os movimentos de massa não tiveram desenvolvimento e, quando do início das reformas, reduziram-se de vez. 0 ator principal das transformações foi o poder superior ${ }^{5}$. E três quartos da composição pessoal da nova elite, que esteve à testa das transformações, foram formados pela nomenklatura anterior. 2) Como observa corretamente I. M . Kliamkin, na maioria das outras revoluções sociais, "em sua fase radical foram resolvidos os problemas da maioria, mas entre nós essa questão não se resolveu de modo algum e não está resolvida até agora" ${ }^{6}$. 3) A realização da revolução social (com mais razão uma Grande) dificilmente deixaria de ser conscientizada pela sociedade que a realizou.

Parece-me que o caminho da Rússia nos anos de 1990 passou não pela revolução, mas por reformas de choque, que provocaram toda uma cadeia de continuadas crises políticas e econômico-sociais (começando com a liberalização dos preços e terminando com a segunda guerra tchetchena). N os marcos desta evolução por cri ses é possível distinguir três etapas substancialmente distintas.

O s anos de 1991-1993 foram marcados pela reforma radical dos institutos políticos e econômicos básicos. 0 resultado principal das reformas foi a abertura do caminho para a redistribuição da propriedade e do poder. As elites dirigentes concentraram-se na real ização das novas possibilidades, praticamente desistindo das reformas seguintes. À massa foi proposto seguir o princípio "a salvação dos afogados é problema dos próprios afogados". O s seus representantes, seguindo o exemplo das elites, passaram a desenvolver distintas formas de atividades legais e subterrâneas, tendo em vista a sobrevivência e, se possível, a melhoria das condições de existência. Sob influência dessa atividade espontânea das massas, surgiram e se desenvolveram gradual mente novos mecanismos sociais de transformação dos diferentes aspectos da vida social, independentes do poder. No lugar dos modos tradicionais de comportamento começaram a manifestar-se novas práticas sociais, correspondentes às condições das instituições modificadas, modificando-as, por sua vez. D esta forma, o processo de transformações sociais não se encerrou, sendo a etapa das reformas orientadas do alto, sucedida pela etapa da transfor ma ção espontânea da sociedade. E ssa etapa conduziu ao desmoronamento final do sistema institucional anterior, ao crescimento gigantesco das contradições sociais, à queda e à informalização da economia e, finalmente, ao default de 1998. 
No começo de 1999, os processos de distribuição e redistribuição da propriedadeestavam basicamente terminados. O s indicadores econômicos, tendo "tocado o fundo do poço", começaram lentamente a crescer e o desenvolvimento da sociedade passou a seguir uma trajetória mais estável. N essas condições, a elite dirigente considerou possível retomar as reformas, destinadas a completar as transformações democrático-liberais.

$N$ essa terceira etapa estamos atualmente. À primeira vista, ela se assemelha à primeira; mas na realidade, elas são distintas. Em 1991-1993, o velho sistema institucional já estava destruído e um novo ainda não tinha conseguido surgir. Por isso o poder teve possibilidade de estabelecer as regras do jogo de acordo com sua concepção, editar novas leis "a partir do zero". Agora, entretanto, a situação alterou-se substancialmente. Enquanto a elite dirigente proveu-se da propriedade privada, no país estabeleceu-se uma nova estrutura institucional, de caráter predominantemente informal, mas não menos rígido. O s elementos dos novos institutos, estando compactamente ajustados uns aos outros, formam mecanismos sociais integrados, apoiados e protegidos por forças sociais poderosas - em primeiro lugar pela burocracia corrupta e pela criminalidade detentora de status legal.

Se se pode caracterizar as reformas gaidarianas ${ }^{7}$ como um ataque dosguardas vermelhos ao socialismo, a atividade dos reformadores atuais lembra mais um assalto à for taleza, guardada pelas forças e grupos a ela contrários. As reformas movem-se muito devagar e, o mais importante é que até mesmo as leis já apro-

\section{O s resultados da transformação sistêmica na R ússia e suas interpretações}

\author{
LENINA POMERANZ
}

Com o ressalta Tatiana Zaslavskaia em seu artigo, existem várias interpretações sobre os resultados da transformação sistêmica por que passou a Rússia desde o início dos anos de 1990, inclusive a dela, trazida para conhecimento dos leitores de Estudos A van çADOS. $N$ ão se trata propriamente de um artigo, mas de uma apresentação feita durante o simpósio anual patrocinado pelo Intertsenter e pela Escola Superior de Ciências Sociais e E conômicas de M oscou, sobre o grande temaPara onde vai a R ússia? (Kuda idiot R ossiia?) e temáticas específicas a cada ano por ele abrigadas. D aí o caráter polêmico que assume, quando discute uma dessas interpretações, defendida pelo cientista político V. M au, muito vinculado à equipe econômica que conduziu por longos anos, ainda que intermitentemente, as reformas econômicas e institucionais que tiveram curso na Rússia a partir do início dos anos de 1990 e que atual mente ocupa a posição de reitor da referida Escola.

Os anais do Simpósio de 2003 ainda não estavam publicados em meados do ano, de maneira que 0 texto relativo à apresentação de V. M au não estava disponível, quando o texto de Zaslavskaia nos foi por ela entregue. As posições desse cientista político são, porém, conhecidas por meio de seus vários escritos, inclusive de um texto não publicado, enviado preliminarmente para um seminário a ser realizado em São Paulo do qual participaria, e ao qual nos foi dado acesso ${ }^{1}$. N ele, $V$. $M$ au expõe a sua tese, sumarizada por Zaslavskaia, sobre a natureza revolucionária da transformação sistêmica russa, atribuindo-a à combinação peculiar de quatro desafios, associados a quatro diferentes processos de transformação: a) o desafio da transição da sociedade industrial para a pós-industrial, que 
vadas defrontam-se com resistências de baixo e muito freqüentemente não são implementadas. Como conseqüência, as mudanças do sistema social constituem resultado de dois elementos paralelos: reformismo objetivado do alto e transformação espontânea de baixo. Com isso, a direção real desse processo define-se não tanto pelas diretrizes do poder e a atividade da sociedade civil, como pelos interesses e relações de força dos diferentes grupos de influência.

\section{0 presente e o futuro: o que vem à frente?}

A fim de que a avaliação dos resultados das reformas realizadas seja completa e objetiva, é necessário, segundo penso, proceder a uma análise da dinâmica, em primeiro lugar da eficácia dos institutos básicos, em segundo lugar, da qualidade da estrutura social e, em terceiro lugar, do potencial humano do país. E comparar as características da sociedade contemporânea indicadas não somente com sua situação de partida, mas também com os objetivos declarados das reformas. Como o formato das apresentações no Simpósio não permite um exame desenvolvido da questão, limitar-me-ei a uma avaliação de princípio sobre o caminho percorrido pela Rússia.

$\mathrm{N}$ ão é preciso demonstrar que o sistema formal-legal das instituições claramente liberalizou-se e democratizou-se; sobre isso muito se falou nas reuniões do Simpósio. Entretanto, esse sistema permanece ainda muito imperfeito. Ele é incompleto e contém muitas normas contraditórias, ineficazes e ilegais ${ }^{8}$. E o mais importante é que parte significativa das novas leis e normas não é reforçada nem por um sistema de coerção, capaz de garantir a sua aplicação, nem por normas culturais informais, que regulam o comportamento dos atores sociais. Como resultado, as normas liberal-democráticas assumem um caráter nominal, enquanto na sociedade, de fato, atuam regras do jogo baseadas não na lei, mas na força do dinheiro, do poder e da violência.

No início da Perestroika, M. G orbachev colocou como tarefa a criação de um estado de direito, encarando-a como condição do ingresso do país na comunidade internacional. D e fato, porém, nos anos passados, a Rússia, nesse sentido, degradou-se. Em vez da modernização do sistema legal, que permitiria uma melhor realização do potencial humano do país e o desenvolvimento vitorioso de suas relações internacionais, as regras do jogo vigentes caíram num estágio mais primitivo, assumindo, em muito, um caráter de barbárie. A anomia cultural, juntamente com a paralisia do judiciário, conduziram a uma expansão jamais vista da criminalidade, inúmeras formas da qual adquiriram estabilidade e se transformaram em prática cotidiana. O s investidores estrangeiros não desejam investir seu dinheiro no desenvolvimento de um país que não é capaz de assegurar garantias legais à sua atividade. E parte significativa dos russos acabaram excluídos da economia e, na realidade, passaram a ser vistos pelo poder, como fardo não necessário.

As transformações institucionais acarretaram movimentos importantes na estrutura so cial ${ }^{9}$. N esse sentido, a divisão social e cultural característica da Rússia 
e da U RSS entre a classe dominante e o restante da sociedade não se reduziu, mas aprofundou-se ainda mais. Agora o pólo mais alto de nossa sociedade é representado por $5-7 \%$ das famílias que concentram em suas mãos mais de metade da riqueza nacional, enquanto o mais baixo é representado por 30-35\%de pobres, total mente distanciados da propriedade. Entre eles estão amplamente representados os "novos pobres" 10 - pessoas saudáveis, qualificadas e ocupadas, mas cujo baixo pagamento pelo seu trabalho não é suficiente para a manutenção mínima de suas famílias.

I númeras pesquisas sociológicas demonstram que o processo de adaptação dos russos às novas condições institucionais nos últimos anos tornou-se mais rápido. De acordo com dados do VCIOM - Centro Russo de Pesquisas da O pinião Pública, em 2002 adaptaram-se à economia de mercado basicamente $85 \%$ dos respondentes (contra 66\%em 1999). Conseqüentemente, reduziu-se a proporção das pessoas que consideram sua situação ruim, sentem profunda insatisfação com a sua vida, tensão, medo e tristeza. Em 1999, elas constituíam aproximadamente $60 \%$, e em 2002 , cerca de $40 \%$

Entretanto, pesquisas mais aprofundadas demonstram que em mais de metade dos casos, a adaptação dos russos baseia-se na mobilidade social decrescente; tem caráter compulsório e não voluntário; conduz ao estreitamento da liberdade individual. As pessoas simplesmente se acostumam com condições piores e gradual mente a elas se submetem. E já não é pequeno o grupo de cidadãos que não puderam adaptar-se e encontram-se em uma situação extremamente teve como resultado o surgimento do núcleo de uma estrutura pós-industrial, identificado com o avanço das indústrias de telecomunicações e eletrônica, e com a diversificação da produção dos ramos químico e metalúrgico e o grande crescimento de instituições de ensino superior; b) o desafio da transformação pós-comunista, que ele considera uma experiência histórica única, da passagem de uma economia estatal para uma economia de mercado; c) o desafio da crise macroeconômica; e d) a realização de uma completa revolução social, nas condições de um Estado fraco, com quase todas as suas instituições praticamente destruídas. A peculiaridade dessa combinação na Rússia estaria na sua realização ao mesmo tempo, no mesmo país. M as $V$. $M$ au não se limita a identificar os elementos que compõem a sua ótica sobre a transformaçã̃o sistêmica, avançando em considerações sobre os seus resultados, que considera vitoriosos, embora não totalmente. Diferentemente de Zaslavskaia, cuja ótica de análise apóia-se no novo sistema social resultante do processo de transformação, particularmente das formas pelas quais se fez a redistribuição da propriedade e do poder, V. M au usa como objeto de análise a estabilização macroeconômica, a estabilização política paralela e a transformação pós-comunista, expressa pela eliminação das características fundamentais do sistema anterior, entre as quais a propriedade estatal. Essa diferença de óticas de análise não é, porém, como pode parecer, uma questão de metodologia; ela expressa, em realidade, diferentes posições em relação à interpretação do que é a Rússia hoje e às perspectivas de seu desenvolvimento.

Para V. M au não se trata de uma mudança de rota, mas de ajustamentos estruturais que permitam enfrentar o que considera o problema dominante da Rússia na atual idade: 0 enfrentamento da crise do sistema industrial e o estabelecimento das bases socioeconômicas da sociedade pós-industrial. Para Zaslavaskaia, como se verá no artigo, é indispensável realizar novo ciclo de reformas institu- 
difícil. Esse grupo até, de acordo com as pesquisas, é constituído por cerca de $15 \%$ ou mais de vinte milhões de pessoas e a eles deve-se agregar, como mínimo, sete milhões de representantes do fosso social (alcoólatras, drogados, sem-teto, ex-presidiários e outros ), não incluídos nas amostras das pesquisas.

Em conclusão, hoje temos uma sociedade dividida socialmente, com um estrato médio sub desenvolvido e parte principal dos cidadãos desprovidos, e em considerável medida lumpenizados. 0 topo não numeroso dessa sociedade está separado de sua maioria por uma enorme distância social. Em comparação com o período soviético, a oposição entre a elite e a massa de trabalhadores aumentou muito e adquiriu um caráter ostensivo de classe. Em um pólo da sociedade concentram-se os recursos de trabalho da sociedade, no outro, o capital produtivo e financeiro.

O s referidos movimentos institucionais e sociais ocasionaram uma influência extremamente negativa sobre a riqueza principal e penhor da força da Rússia o seu potencial humano. 0 número de habitantes, o estado de sua saúde, o seu equilíbrio no gênero e na idade, o seu nível de educação, os objetivos e valores subjetivos, enraizados em sua cultura comportamental, definem de maneira de cisiva o futuro próximo e longínquo da Rússia.

Pretendia-se que a Perestroika e as reformas liberais-democráticas permitissem não só utilizar mais eficazmente o potencial humano do país, como também assegurar a sua reprodução ampliada. $\mathrm{N}$ a realidade, o resultado obtido foi 0 contrário. A mortalidade da população aumentou muito e os nascimentos diminuíram em quase o dobro, o que provocou uma redução da população na maioria das regiões, compensada só parcialmente e cada vez mais debilmente pelo influxo de russos dos países da CEI - Comunidade dos Países I ndependentes. 0 desmoronamento dos serviços gratuitos de saúde, diante do fraco desenvolvimento dos serviços médicos privados e da inacessibilidade deles para a maioria dos russos, constituiu um fator importante para a queda dos padrões de saúde e da prematura mortalidade da população. Segundo testemunho dos médicos, mais de metade da população adulta do país precisa de ajuda psicológica e psiquiátrica. Entrementes, os dispêndios com a saúde constituem na Rússia somente 3\% do PIB, sabendo-se que nos U SA el es são iguais a 14\% e na E uropa, a 8-10\% N ão deixa de ser importante também o fato de a Rússia estar próxima de alcançar 0 recorde em freqüência de suicídios.

$\mathrm{N}$ a esfera da educação, que propicia a reprodução e o crescimento do potencial humano do país, observa-se uma acentuada polarização. De um lado, fortalece-se a educação de elite, propiciando aos russos prestigiosas universidades nacionais e estrangeiras. D e outro lado, o nível da educação escolar obrigatória, pela primeira vez na prática do Estado foi reduzi do de onze para nove anos, enquanto mais de $10 \%$ das crianças em idade escolar não freqüentam a escola. Como conseqüência, às casernas chegam recrutas que não sabem ler e escrever, 0 que não ocorria há dezenas de anos. Cerca de dois milhões de crianças órfãs e 
abandonadas vivem sem família nos sótãos e porões, dedicando-se basicamente ao roubo. Tornando-se adultos, eles nunca poderão tornar-se plenos e corretos cidadãos. A ciência vive pesada crise. Exatamente quando o país se defronta com os desafios do pós-industrialismo, o seu potencial cultural e científico-tecnológico continua a reduzir-se. Se essa tendência continuar, a Rússia, em futuro não distante, se transformará em país puramente periférico, com atrasada economia primária, não desempenhando influência política relevante nas questões da comunidade mundial.

Para romper essa tendência, alcançar crescimento do potencial humano e harmonização da estrutura social, só existe um meio - realizar novo ciclo de reformasinstitucionais, orientadassocialmente. 0 sistema de instituições e práticas sociais criado não corresponde nem aos interesses vitais da sociedade, nem aos interesses geopolíticos do país e por isso precisa ser radicalmente reformado. $M$ as ele satisfaz plenamente os interesses egoístas dos grupos em cujas mãos se concentram tanto as regras de gerenciamento da sociedade como os recursos de seu desenvolvimento.

A elite dominante não tem pressa para mudar sua política social, voltar o rosto em direção ao povo. E o povo trabal hador, por ora, ainda não está pronto para falar com a elite em nível de igualdade e defender de forma auto-suficiente os seus interesses. Por isso, pode-se esperar que, ao longo de algum tempo ainda, as tendências acima referidas mantenham sua força. A divisão entre o poder e a sociedade deve aprofundar-se mais, a elite, enriquecer-se por conta da cionais, orientadas socialmente; portanto, o problema dominante é o problema social, perpassado que é pela concentrada distribuição de renda e pelas conseqüências negativas das transformações sobre o potencial humano do país, expressas nos seus indicadores demográficos e na deterioração dosindicadores de educação e de saúde da população.

0 debate sobre os resultados das tranformações sistêmicas é dominante atualmente, porque é consensual a necessidade de definir uma estratégia para o desenvolvimento do país, envolvendo inclusive a indicação de seus agentes intervenientes. E essa definição passa por uma interpretação do que é hoje o país, depois dos quinze anos de transformação sistêmica. N ão por acaso, o simpósio anual do I ntertsenter não se realiza mais sob o grande tema de Para ondevai a R ússia?, abrigandose agora o debate da inteligentsia de todo o país dele participante sob o tema Onde che gou a R ússia?.

Com a publicação do artigo de T. Zaslavaskaia, começamos a acompanhar o debate.

Nota

1 Economic and Political R esultsfor 2001 and Prospectsfor Strenghtening E conomic Growth. M imeo., abr.-maio 2002.

Lenina Pomeranz é professora associada da Faculdade de E conomia e Administração da U SP, e pesquisadora do Instituto de Estudos Avançados da U SP. Autora da tese de livre-docência Tranformações sistêmicas e privatização na R ússia, U SP, 1995. 
continuada apropriação da renda resultante da exploração dos recursos naturais, e o povo trabalhador, empobrecer e perder posição social. $M$ as isso não pode prolongar-se infinitamente. E qual será, exatamente, a saída dessa "estúpida infinidade" - pacífica e civilizada ou explosiva, parece-me que é cedo para falar.

N otas

1 O s grifos são da autora, da mesma forma que os demais que surgirem em diante no texto (N. da T.).

2 Conforme artigo de V. M au nos anais do Simpósio.

3 Ver V. P. D anilov, "Padenie sovetskovo obshestva: colaps, institutsionalnyi krisis ili termidorianskii perevorot? ( $Q$ ueda da sociedade soviética: kolapso, crise institucional ou golpe termidoriano?)", em K uda idiot R ossia? M oscou, M VSSE N, Intertsenter, 1999, pp. 11-28.

4 Ekonomika per ekhodnovo perioda. Vedenie (E conomia do período de transi ção. I ntrodução). M oscou, IPPP, 1999, pp. 1-13.

$5 \mathrm{~N}$ a opinião de L. F. Shevtsova, na Rússia a questão refere-se a um revolucionarismo (revolutsi on ost) limitado sistemicamente, o qual não conduziu à mudança da essência do poder: este até agora permanece nos limites do paradigma tradicional russo de monosubjetividade (monosubieknost)... continua mantendo-se uma grandeza que se auto-reproduz".

6I. M . Kliamkin, Vystupleniena konferentsii "D eciat let poseA vgusta. Predpocylki, itogui i perspektivy rossii skoi tranformatsi i". (A presentação na Conferência Dez anos após agosto. Pressupostos, con clusões e per spectivas da transfor mação russa). M oscou, Fundação Liberalnaia M issia (M issão Liberal), 2002.

7 As primeiras reformas, dos anos de 1991-1993, foram conduzidas por Egor Gaidar, então 1 ㅇ M inistro do governo leltsin (N. da T.).

$8 \mathrm{Na}$ teoria liberal do direito, são consideradas ilegais as leis e normas que não correspondem à concepção de justiça das massas. Sobre isso, mais detalhadamente, consultar T. I. Zaslavskaia e M. A. Shabanova, K probleme institutsionalisatsi i nepravovykh sotsialnykh praktik v R ossii:sfera truda (Sobre o problema da instituci onalização das práticas sociais não legais na Rússia: efera do trabalho). M ir Rossii (M undo da Rússia), 2002, n. 2, pp. 6-8.

$9 \mathrm{M}$ ais detalhadamente ver em: $Z$. T. Golenkova, Ocnovnye tendentsi transformatsi $i$ sotsialnykh neravenstv (Princi pais ten dências de transformação das des gual dades sociais). In: Rossia: Transformiriusheisia O bshestvo (R ússia: Soci edade em Tranformação). M oscou, Kanon-Press Ts., 2001, pp.90-103; Coletivo de autores sob a direção de T. M aleva. Srednii klass v R ossii : kolitchestvenye e katchestvenye otsenki (A classe média na R ússia: avaliaçõesquantitativase qualitativas). M oscou, TEIS, 2000. T. I. Zaslavskaia, Sotsialnaia struktura sovremenovo rossi iskovo obshestva// Sotsi etal nai a transformatsia rossi iskovo obshestva. D eiatel nostno-strukturnaia kontseptsia (Estrutura social da soci edaderussa contemporânea/ / T ransfor mação social da soci edaderussa. C oncepção operativo-estrutural). M oscou, D elo, 2002, pp. 370-400. 
10 A autora aqui faz contraponto com os chamados "novos ricos" resultantes da transformação social (N. T.).

RESUMO - O ARTIGO constitui a versão escrita de uma apresentação feita pela autora, em 2003, em mesa-redonda organizada no âmbito do Simpósio realizado anualmente pela E scola Superior de M oscou de Estudos E conômicos e Sociais, sob o grande tema Para onde vai a R ússia? Trata-se de uma polêmica com o cientista político Vladimir M au, atualmente reitor da referida E scola, a pro pósito dos resultados da transformação sistêmica que teve lugar na Rússia, a partir do início dos anos de 1990, sugerindo, a partir dos mesmos, um caminho para delineamento de um futuro distinto para o país.

A BSTRACT - THE ARTICLE is a written version of the exposition done by the autor in 2003, in a Round Table organized within the symposium Whiter R ussia?, that takes place annually under the auspices of the M oscow School of Social and Economic Studies. In the article she disputes with Vladimir M au, a political scientist, now Rector of the referred School, about the results of the R ussian systemic transformation of the 90 's and suggests, on the basis of these results, a different path for the future development of the country.

Tatiana Zasavskaia é socióloga, membro da Academia R ussa de Ciências e diretora do E scola Superior de Ciências E conômicas e Sociais de M oscou e do I ntertsenter.

Tradução por Lenina Pomeranz. O original em russo - C hto pereji to R ossi ei i chto u neió vperedi ? - encontra-se à disposição do leitor no IEA-U SP para eventual consulta.

Texto recebido e aceito para publicação em 5 de setembro de 2003. 